\title{
Performance Analysis of the Linear Launcher Motor via Modelling and Simulation for Light Electric Vehicles
}

\author{
Norramlee Mohamed Noor ${ }^{1,2 *}$, Ishak Aris ${ }^{1 *}$, Norhisam Misron', Suhaidi Shafie ${ }^{1}$ \\ and Parvez Iqbal ${ }^{3}$ \\ ${ }^{1}$ Department of Electrical and Electronics, Faculty of Engineering, Universiti Putra Malaysia, 43400 Serdang, \\ Selangor, Malaysia \\ ${ }^{2}$ Electrical Electronic Automation Section, University Kuala Lumpur, Malaysian Spanish Institute, Kulim Hi- \\ Tech Park, 09000 Kulim, Kedah, Malaysia \\ ${ }^{3}$ International University of Business Agriculture and Technology-IUBAT, 4 Embankment Drive Road, Sector \\ 10, Uttara Model Town, Dhaka 1230, Bangladesh
}

\begin{abstract}
This research aimed to analyse the linear launcher motor (LM) for the light electric vehicle (EV) application that generated a linear movement. LM will replace the piston engine and eliminate the internal combustion engine (ICE) issues namely engine weight and friction at piston wall. The finite element magnetic softwares (FEMs) for a magnetic field was described in this study by predicting the magnetic flux relationship using a $2 \mathrm{D}$ J-Mag software. In addition the finite element (FE) analysis was used to simulate the linear launcher motor by using MATLAB/Simulink software. The results show that the linear launcher motor can generate the axial force, speed, and displacement of with and without load. The maximum force without load was $\sim 1.6 \mathrm{kN}$ while force with load was $\sim 1.4 \mathrm{kN}$ at $100 \mathrm{~A}$ supplied. The comparison between the force without load and load force was different by $12.5 \%$.
\end{abstract}

Keywords: Electric vehicle, finite element magnetic softwares, linear launcher motor

ARTICLE INFO

\section{Article history:}

Received: 28 November 2019

Accepted: 30 March 2020

Published: 22 January 2021

DOI: https://doi.org/10.47836/pjst.29.1.05

E-mail addresses:

noramlee@unikl.edu.my (Norramlee Mohamed Noor)

ishak_ar@upm.edu.my (Ishak Aris)

norhisam@upm.edu.my (Norhisam Misron)

suhaidi@upm.edu.my (Suhaidi Shafie)

akm.parvez.iqbal@gmail.com (Parvez Iqbal)

* Corresponding author

\section{INTRODUCTION}

The automobile industry in the coming years will face serious problems such as global warming and fossil fuel resources. This is because most vehicles on the road today use a large amount of internal combustion engine (ICE), which is the burning engine process that causes environmental pollution. According to a recent study, ICE by using 
gasoline combustion is the most polluted air at about 28\% (Andersson, 1991; Noor et al., 2019a). Compression piston rings and cylinder walls are represented by a significantly higher power loss in modern ICE that accounts for about $35 \%$ of the overall mechanical friction engine (Noor et al., 2019b; Bolander et al., 2005). To overcome these problems, various types of research and development for next-generation vehicles have been pursued from different angles (Chan, 1996).

This research aimed to provide the opportunity to develop the analytical study of a linear launcher motor (LM) for electric vehicle (EV) application, known as the linear electromagnetic motor (EMM). The finite element magnetic softwares (FEMs) for a magnetic field are described by predicting the magnetic flux relationship using 2D J-Mag software. In addition, the finite element (FE) analysis was used to simulate the linear launcher motor by using MATLAB/Simulink software. Finally, the results show that the linear launcher motor could generate axial force, speed, and displacement of with and without load.

\section{LINEAR MOTIONS}

The application of linear motion is currently more challenging than ever due to faster methods, more accurate positioning, longer life, less maintenance, less moving parts, and endless lists (Miler, 2006). There are various types of engines in the global market that have a different number of cylinders namely the inline engine, $\mathrm{V}$ engine, and flat-opposed engine. Every cylinder contains a piston that moves up and down inside the engine, where it is connected through an individual connecting rod to a universal crankshaft.

\section{Concept of Linear Launcher Motor}

The linear launcher motor is a conventional motor in which projectile moves in a linear direction rather than in the rotation (Bedajangam \& Jadhav, 2013; Mclean,1988; Say \& Taylor, 1982; Matsch \& Morgan, 1986; Sgobba, 2011). This kind of linear launcher may have a set of solenoids placed alongside the moving object. This linear launcher looks like a tubular launcher, which primarily consists of a simple row of coaxial coils. The linear launcher is divided into three categories including coil-gun, rail-gun, and induction launcher (Laithwaite, 1975; Gieras \& Piech, 1999; Beaty \& Kirtley, 1998).

\section{Structure Linear Launcher Motor Model}

The structure of linear LM is similar to a linear motor that is a solenoid actuator. A York and mover are the key components of this linear LM as shown in Figure 1. They are fabricated using materials such as mild steel AISI 1008 due to its good magnetic properties that contain $8-13 \%$ of carbon (Chemerys, 2001). The coil used is a copper wire material. Table 1 presents the parameter of the linear LM model. 


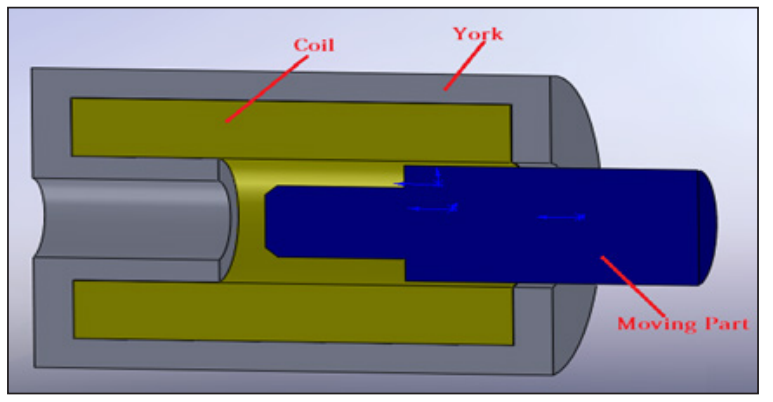

Figure 1.Structure of linear LM model

Table 1

The parameter of the linear LM model

\begin{tabular}{lcc}
\hline Item & Parts & Unit (mm) \\
\hline \multirow{3}{*}{ Coil } & Diameter wire & 4.1 \\
& Height of coil & 39.75 \\
\multirow{3}{*}{ Yoke } & Length of coil & 224.5 \\
& Back Yoke Inner & 20 \\
Moving Part & Back Yoke length & 265 \\
& Plunger diameter & 80 \\
\hline Parts & Plunger length & 121.2 \\
\hline Coil wire & & Materials \\
Yoke & & Copper \\
Plunger & & Mild steel AISI 1008 \\
\hline
\end{tabular}

\section{Method of the linear LM calculation}

There are two types of calculations used to predict the linear LM, which are induction of coil and axial fields of finite coil.

\section{Inductance of Coil}

Figure 2 shows the air core coil and magnetic flux surrounding the conductor.

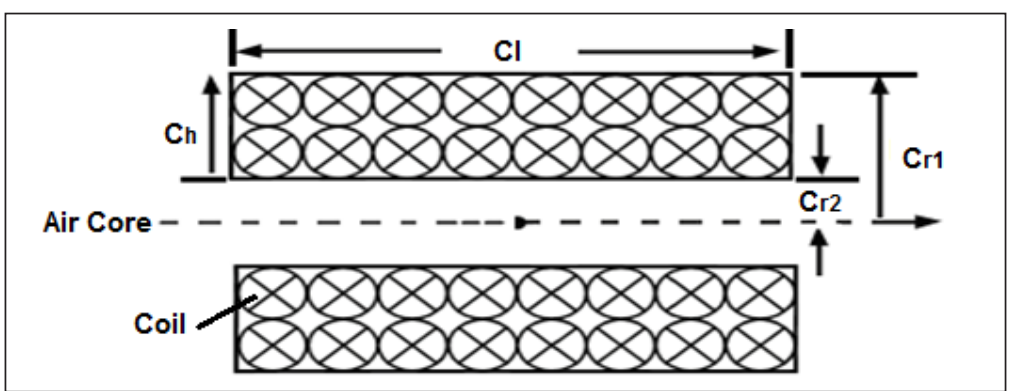

Figure 2. Cross-section of the multi-layer coil 
The inductance of an air-core coil can be calculated using Equation 1, the Wheeler' formula (Johnson \& Francis, 2007; Wheeler, 1982).

$$
L=\frac{0.0315(N C r)^{2}}{6 C r+9 C_{l}+10 C_{h}}
$$

Where, $\mathrm{L}=$ inductance in $\mu H ; \mathrm{N}=$ Total number of turns; $\mathrm{Cr}=\left(C r_{1}+C r_{2}\right)=$ average radius in mm; $C_{l}=$ Coil Length (along axis) in $\left.\mathrm{mm} ; C_{h}=C r_{2}-C r_{1}\right)=$ Thickness of the winding is in $\mathrm{mm}$.

\section{Axial Fields of Finite Coil}

Figure 3 shows the finite coil of the solenoid. The magnetic is measured according to $\mathrm{x}$-plane.

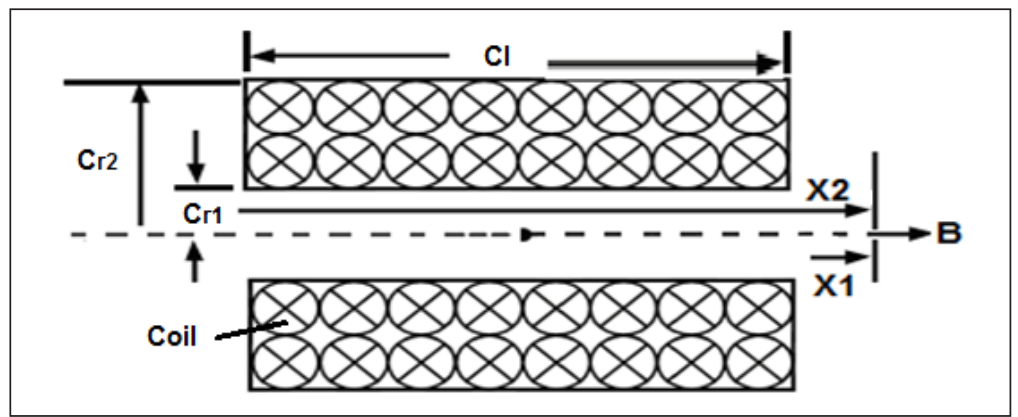

Figure 3: Solenoid in the cross-section view

The fields of a finite solenoid show that at each point, the axes are determined using Equation 2 (Engle et al., 2005; Wheeler, 1982).

$$
B=\frac{\mu_{0 I n}}{2(\operatorname{Cr} 2-\operatorname{Cr} 1)}\left[x_{2} \ln \frac{\sqrt{C r_{2}^{2}+X_{2}^{2}+C r_{2}}}{\sqrt{C r_{1}^{2}+X_{2}^{2}+C r_{1}}}-x_{1} \ln \frac{\sqrt{R_{2}^{2}+X_{1}^{2}+R_{2}}}{\sqrt{R_{1}^{2}+X_{1}^{2}+R_{1}}}\right]
$$

Where, $\mathrm{B}=$ magnetic fields; $\mu_{0}=$ Permeability constant; $\mathrm{I}=$ Current flow in the coil; $\mathrm{n}=$ number of turns; $C_{l}=$ coil Length in $\mathrm{mm} ; C r_{1}=$ Inside radius in $\mathrm{mm}, C r_{2}=$ Outside radius in $\mathrm{mm}, X_{1}$ and $X_{2}=$ Distance in $\mathrm{mm}$.

\section{SIMULATIONS, RESULT AND DISCUSSION}

\section{Dynamic Simulation}

The experiment aimed to revise the possible measures of the electromagnetic flux properties in the coil and to validate the simulation of the linear LM model. The coil was made using 
copper wire (type $12 \mathrm{AWG}$ ) and the diameter of the coil was $4.1 \mathrm{~mm}$ with 400 turns. Figures 4, 5 and 6 display the view of the 2D-JMag model implemented in the FEMs program. Figure 4 shows the magnetic flux density is as shown in a contrasting colour and spectrum. The red colour of the magnetic flux density had the highest value that should be avoided followed by the blue region occured in the air. Therefore, the overall magnetic flux density contour in this research was acceptable and below 2.0 Tesla when 150A current was applied.

Figure 5 is the flux line model that is implemented as a function of time for a better analysis of the simulation result. Figure 6 shows the mesh size on edge of mover at $1 \mathrm{~mm}$, for the coil at $6 \mathrm{~mm}$ and for iron at $5 \mathrm{~mm}$.

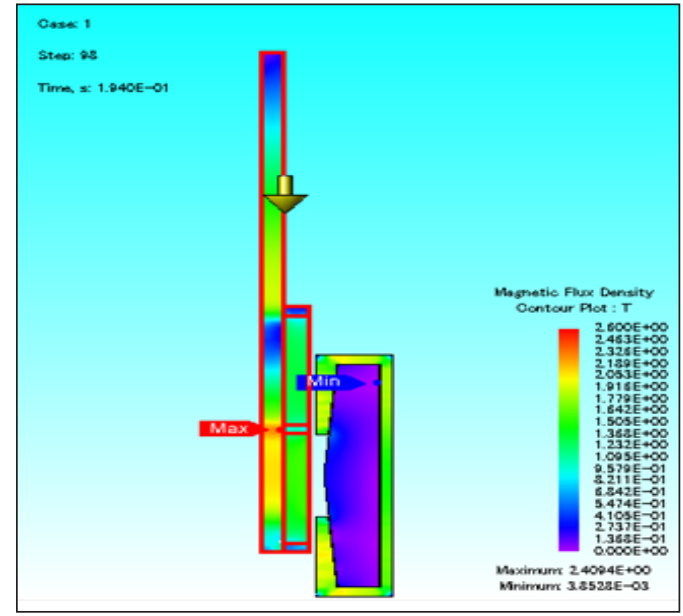

(a)

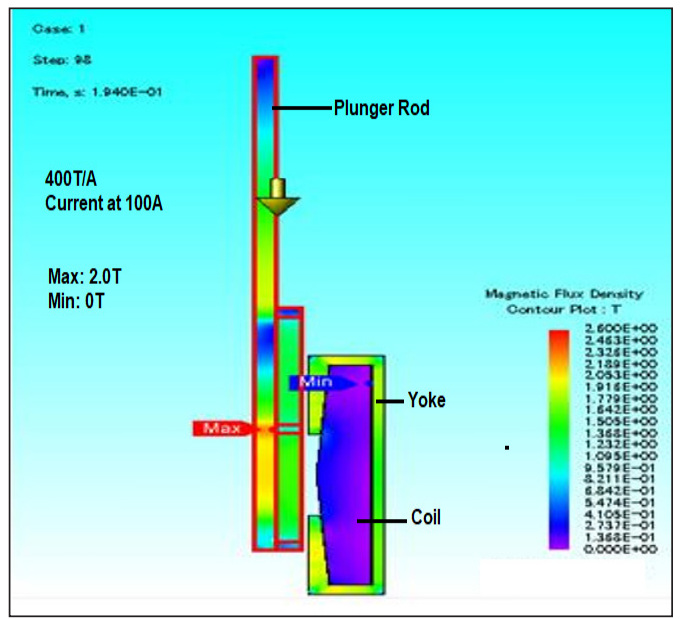

(b)

Figure 4. Magnetic flux density: (a) Before; and (b) After

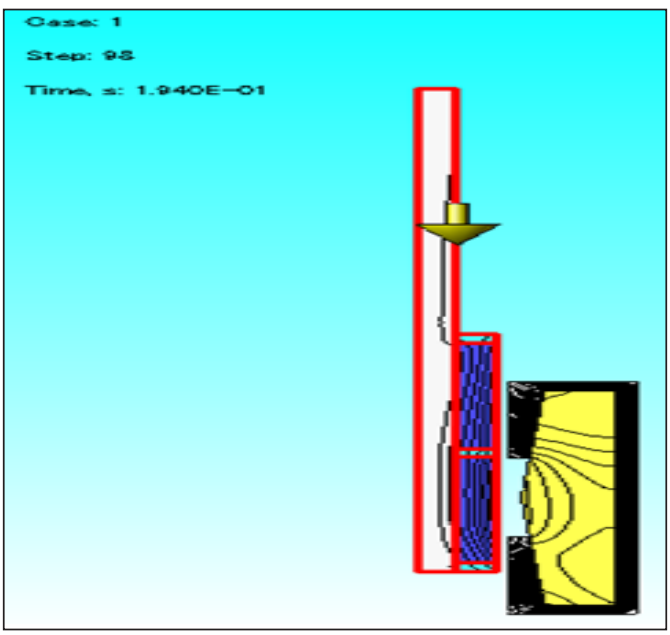

(a)

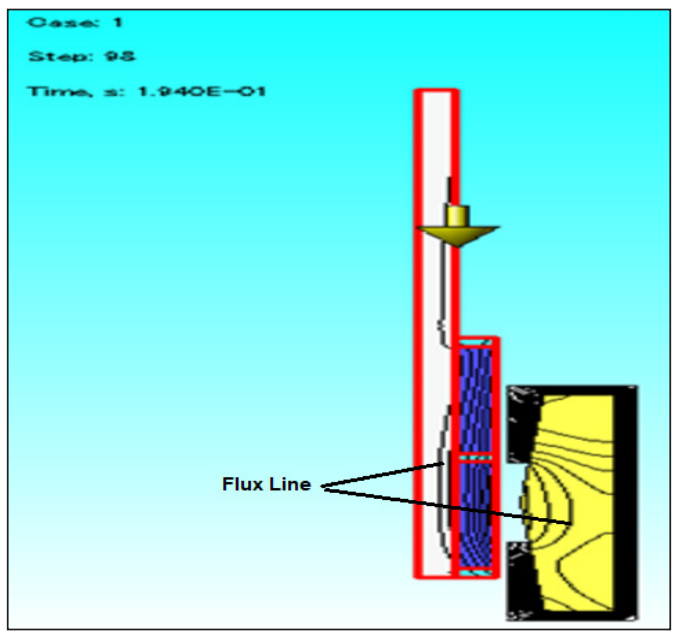

(b)

Figure 5.Flux Line: (a) Before; and (b) After 


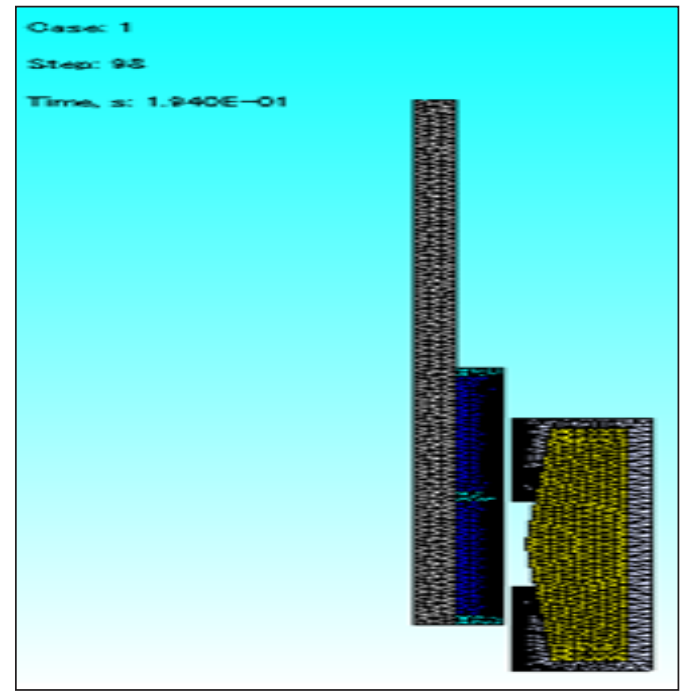

(a)

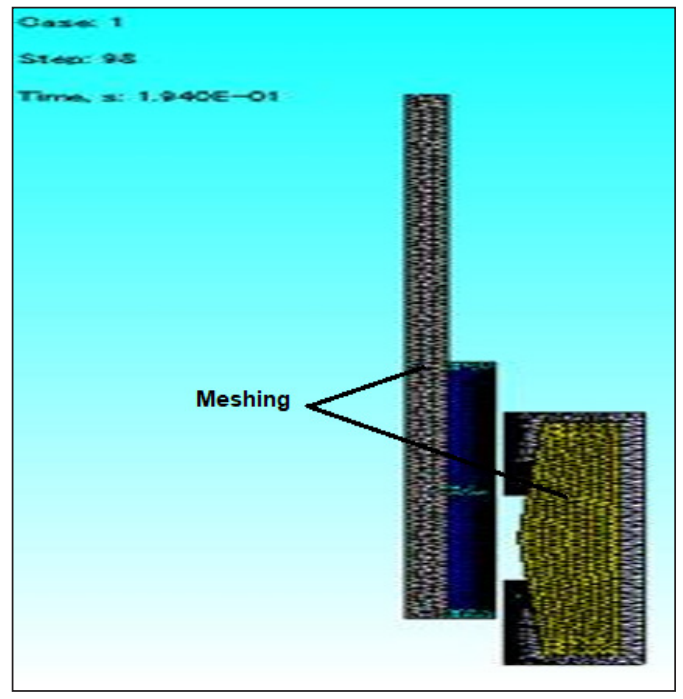

(b)

Figure 6. Meshing: (a) Before; and (b) After

\section{Static Simulation}

The combination of JMAG_RT file to MatLab/Simulink shown in Figure 7 was conducted for two situations; with load and without load. The simulation result of the linear LM model without load and with load in terms of force, speed, and displacement.

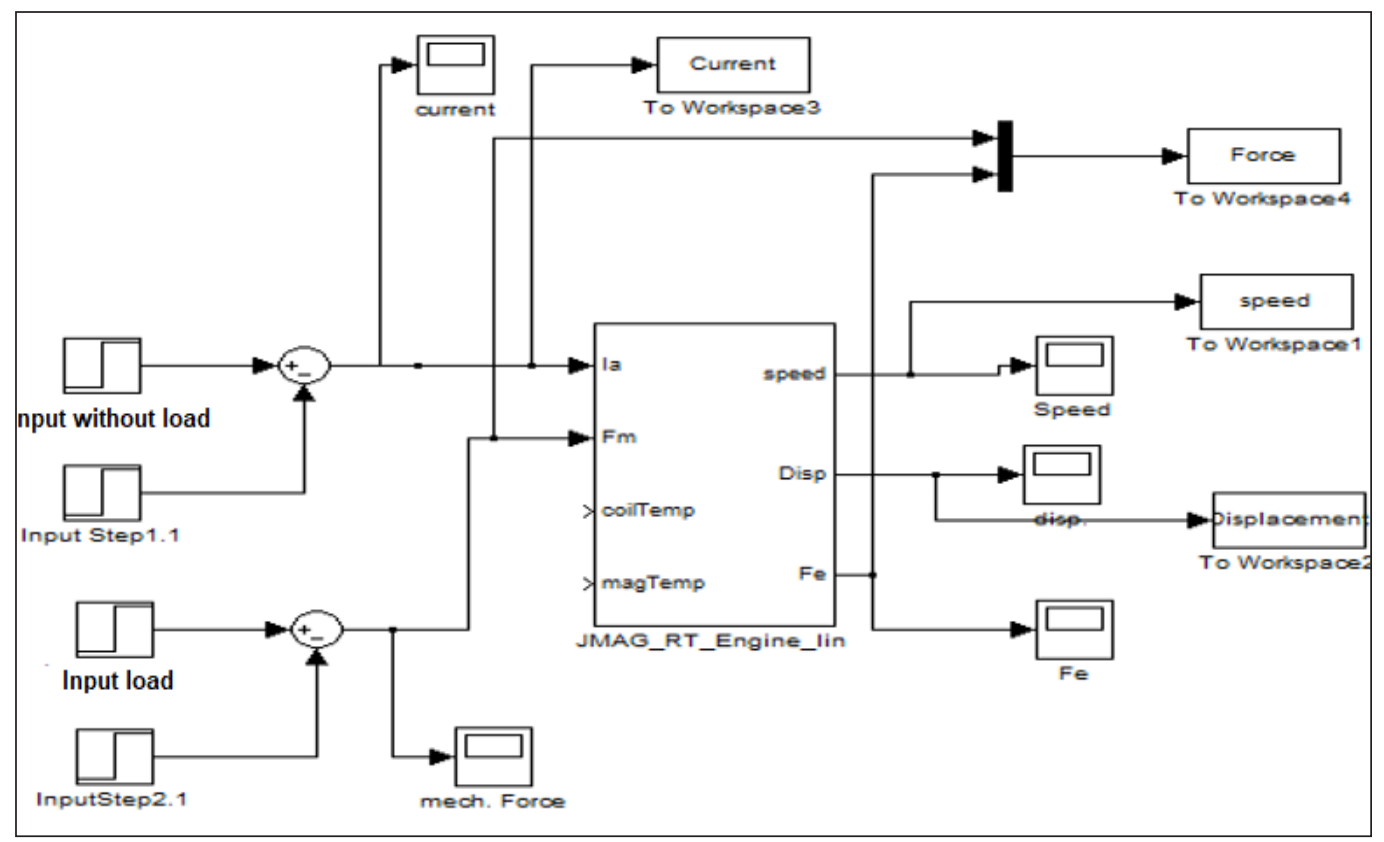

Figure 7. MATLAB/Simulink for linear LM model 


\section{Force}

The graphs in Figures 8 and 9 show the relationship between force without load and load against time. Both graphs showed that the maximum force of linear LM without load was $\sim 1.6 \mathrm{kN}$ while the force load was $\sim 1.4 \mathrm{kN}$ at $100 \mathrm{~A}$ supplied. Therefore, if the current is rising, the force is also increasing for both without load and load. The comparison between the force without load and load force is $12.5 \%$.

\section{Speed}

The graphs in Figures 10 and 11 showe the relationship between the speed of without load and load against time. Both graphs showed that the maximum speed of linear LM without load was $\sim 6.1 \mathrm{~m} / \mathrm{s}$ while the speed load was $\sim 2.5 \mathrm{~m} / \mathrm{s}$ at $100 \mathrm{~A}$ supplied. Therefore, if the current is rising the speed is increasing for both without load and load. The comparison between the speed without load and load speed was $~ 59 \%$.

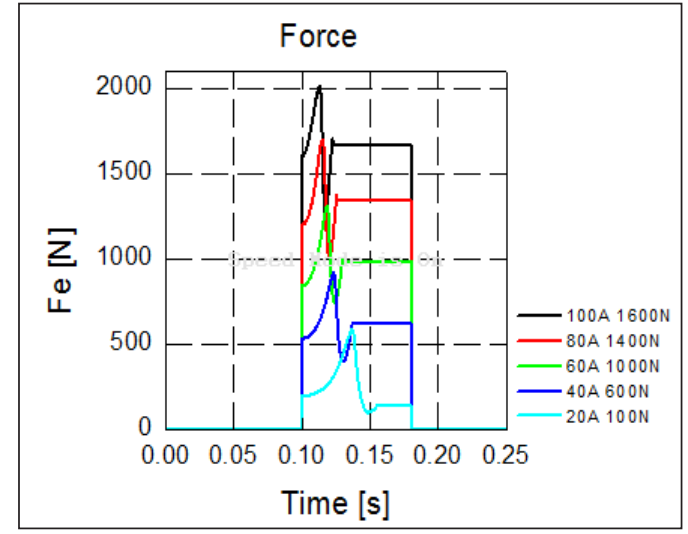

(a)

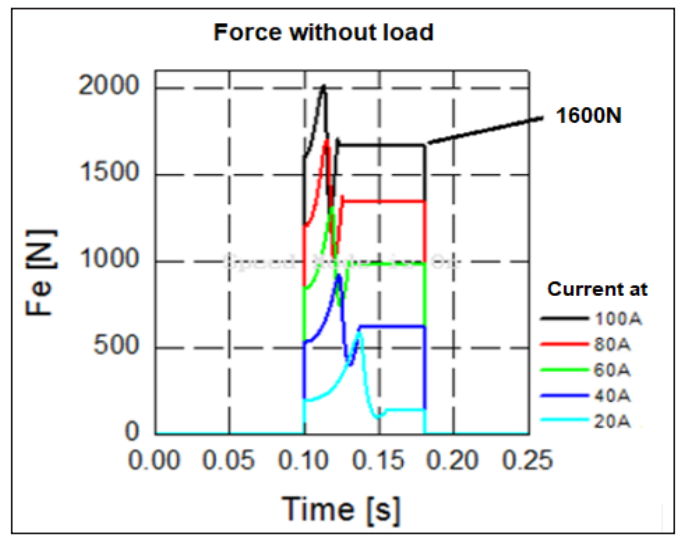

(b)

Figure 8. Force without load: (a) Before; and (b) After

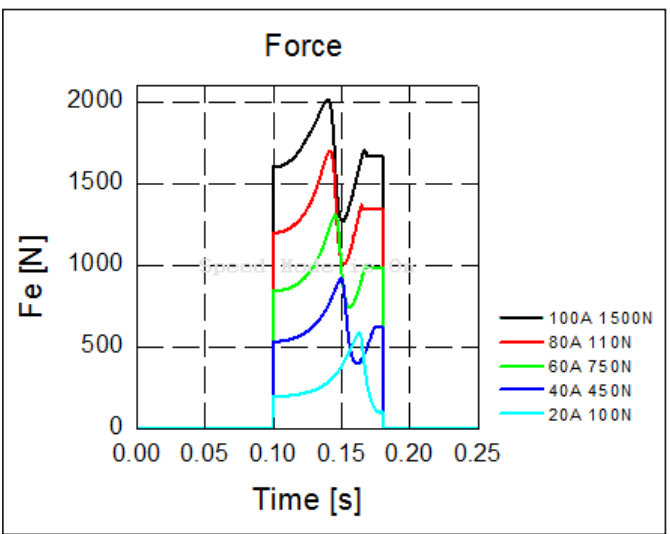

(a)

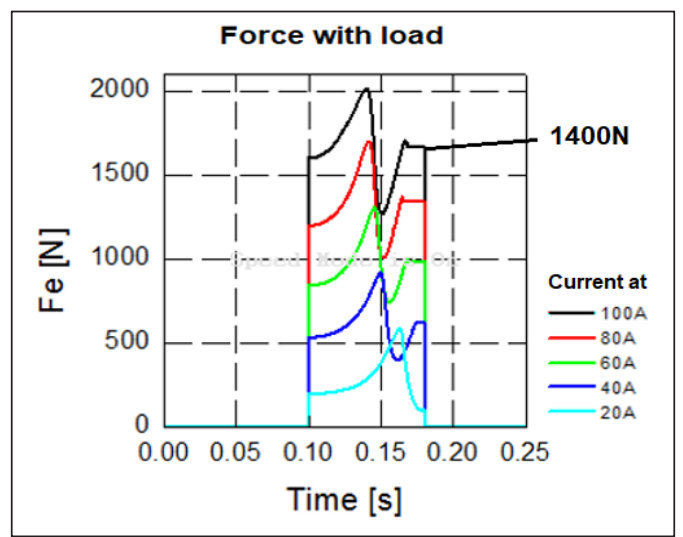

(b)

Figure 9. Force with load: (a) Before; and (b) After 


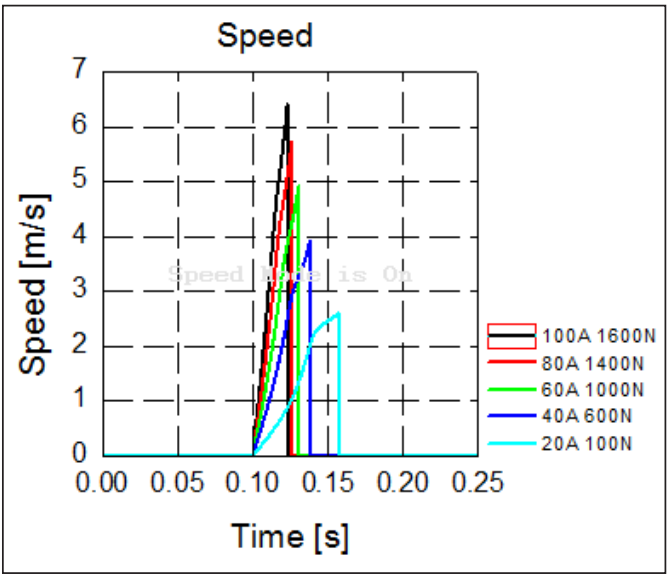

(a)

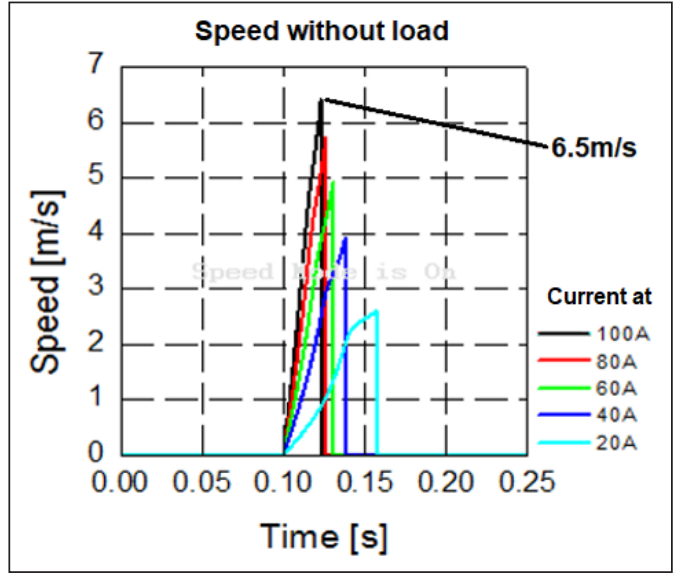

(b)

Figure 10. Speed without load: (a) Before; and (b) After

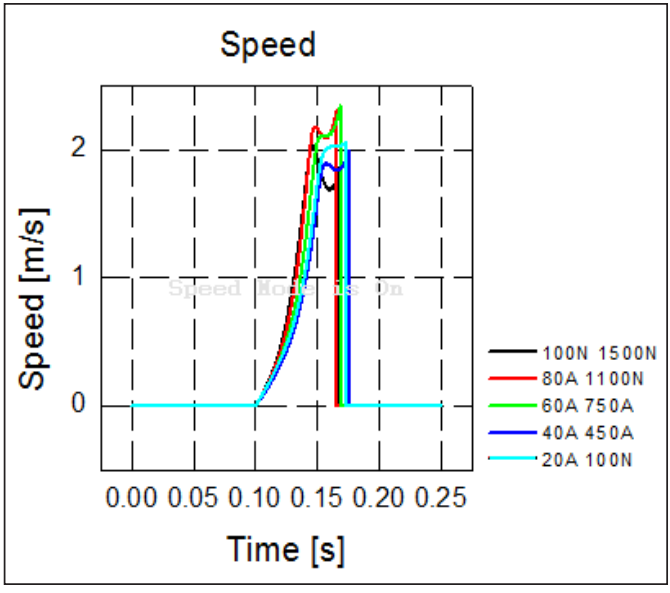

(a)

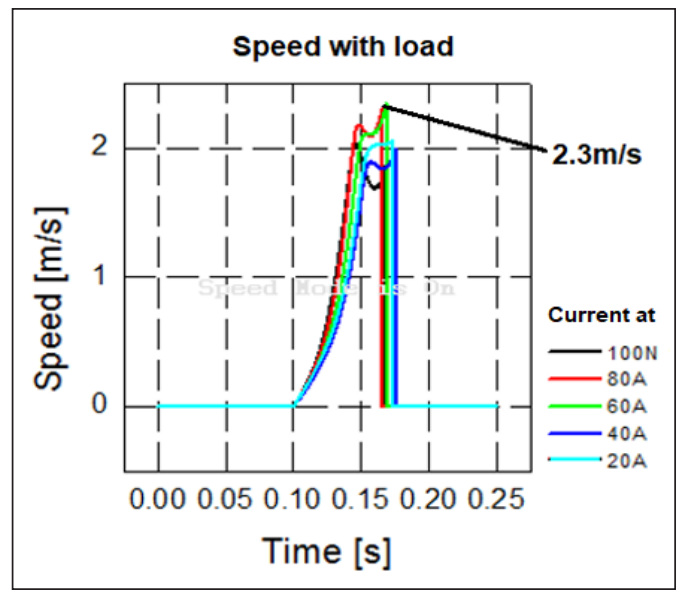

(b)

Figure 11. Speed with load: (a) Before; and (b) After

\section{Displacement}

The graphs in Figures 12 and 13 present the relationship between the plunger displacement of without load and load against time. Both graphs showed that maximum distance produced was $75 \mathrm{~mm}$ at $100 \mathrm{~A}$ supplied. If the current was increased, therefore the value of the plunger distance was constantly fixed at $75 \mathrm{~mm}$ for both with and without load.

\section{CONCLUSIONS}

The design and simulation of linear launcher motor were discussed in this study. The analytical method to predict the linear launcher motor was presented by using 2D-Jmag and MATLAB/Simulink. The performance of the linear launcher motor can generate axial 


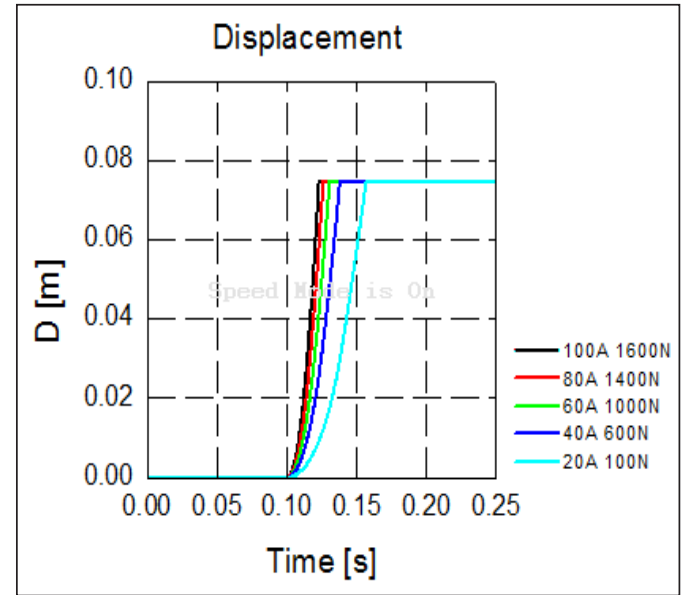

(a)

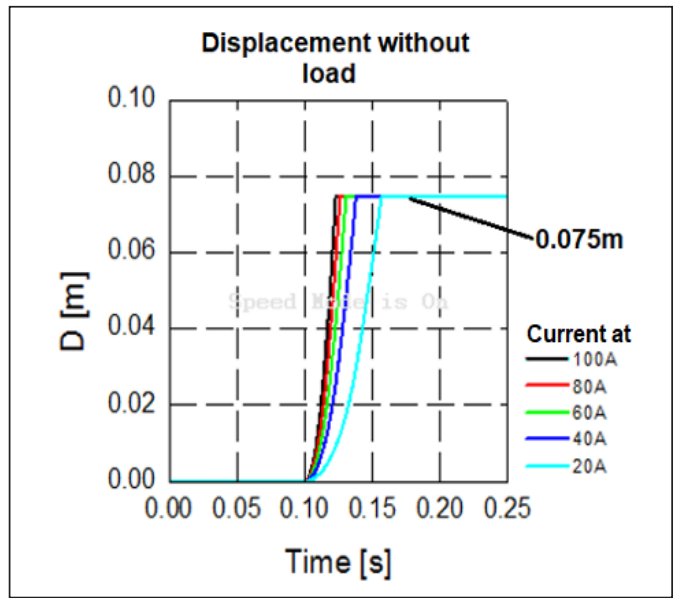

(b)

Figure 12. Displacement without load: (a) Before; and (b) After

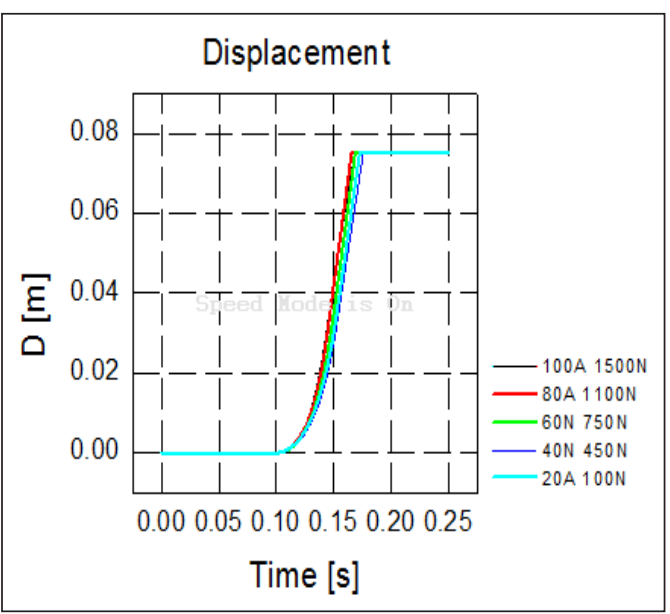

(a)

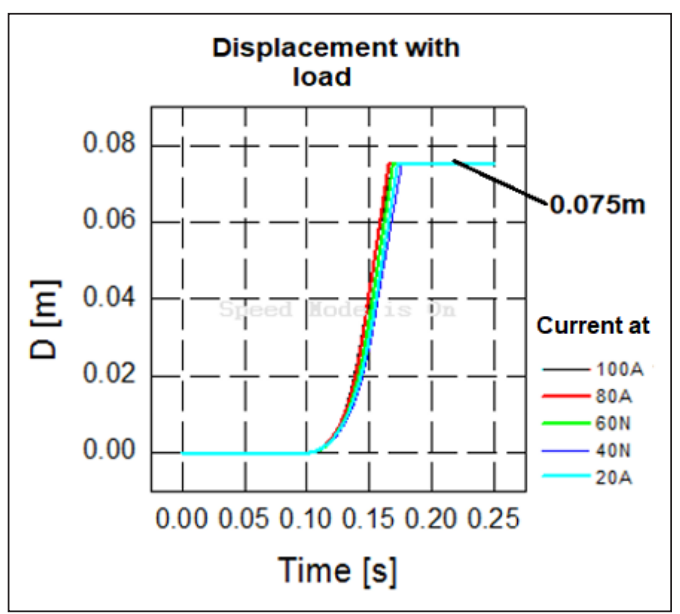

(b)

Figure 13. Displacement with load: (a) Before; and (b) After

force, speed, and displacement of with and without load such as the maximum force without load was $\sim 1.6 \mathrm{kN}$ and force with load was $\sim 1.4 \mathrm{kN}$ at $100 \mathrm{~A}$. Therefore, the comparison between the force without load and load force was $12.5 \%$.

\section{ACKNOWLEDGEMENT}

The authors would like to thank Universiti Putra Malaysia (UPM) and UniKL MSI for providing financial support to carry out the research project. We would also like to express our gratitude to all my friends at UPM and UniKL MSI who have guided us during the research period 


\section{REFERENCES}

Andersson, B. S., (1991). Company perspectives in vehicle tribology-Volvo. Tribology Series, Elsevier, 18, 503-506. doi: https://doi.org/10.1016/S0167-8922(08)70168-8

Beaty, H. W., \& Kirtley, J. L. (1998). Electric motor handbook. New York, USA: McGraw-Hill Education.

Bedajangam, S. K., \& Jadhav, N. P. (2013). Friction losses between piston ring-liner assembly of internal combustion engine: A review. International Journal of Scientific and Research Publications, 3(6), 1-3.

Bolander, N.W., Steenwyk, B. D., Sadeghi F., \& Gerber, G. R., (2005). Lubrication regime transitions at the piston ring-cylinder linear interface. Procedings IMechE Part J: Engineering Tribology, 219(1),19-31. doi: https://doi.org/10.1243/135065005X9664

Chan, C. (1996, August 9). An overview of electric vehicle technology-challenges and opportunities. In Proceedings of the 22nd International Conference on Industrial Electronics, Control, and Instrumentation (pp. 1-6). Taipei, Taiwan. doi: 10.1109/IECON.1996.570892

Chemerys, V. T. (2001). Review of the recent works of Ukrainian authors in the fields of electromagnetic acceleration and related topics. IEEE Transactions on Magnetics, 37(1), 16-24. doi: 10.1109/20.911782

Engle, T. G., Nunnally, W. C., \& Neri, J. M. (2005). Development of a medium-bore high-efficiency helical coil electromagnetic launcher. IEEE Transactions on Magnetics, 41(11), 4299-4303. doi: 10.1109/ TMAG.2005.857900

Gieras, J. F., \& Piech, Z. J. (1999). Linear synchronous motors: Transportation and automation systems. Boca Raton, Florida: CRC Press.

Johnson, A. J., \& Francis, C. M. (2007). Elastic waves in electromagnetic launchers. IEEE Transactions on Magnetic, 43(1),141-144. doi: 10.1109/TMAG.2006.887443

Laithwaite, E. R. (1975). Linear electric machines-A personal view. Proceedings of the IEEE, 63(2), 250-290. doi: 10.1109/PROC.1975.9734

Matsch, L. W., \& Morgan, J. D. (1986). Electromagnetic and electromechanical machines. New York, USA: Wiley.

Mclean, G. W. (1988). Review of recent progress in linear motors. IEEE Proceedings B - Electric Power Applications, 135(6), 380-416. doi: 10.1049/ip-b.1988.0042

Miler, J. M. (2006). Hybrid electric vehicle propulsion system architectures of the e-CVT type. IEEE Transactions on Power Electronics, 21(3), 756-767. doi: 10.1109/TPEL.2006.872372

Noor, N. M., Aris, I., Arof, S., Ismail, A. K., Shamsudin, K. A., \& Misron, N. (2019a). Analytical study of a cylindrical linear electromagnetic pulsing motor for electric vehicles, progress in engineering technology. In M. H. A. Bakar, M. S. M. Sidik \& A. Öchsner (Eds.), Progress in Engineering Technology (pp. 67-82). Cham, Switzerland: Springer. doi: https://doi.org/10.1007/978-3-030-28505-0_6

Noor, N. M., Aris, I., Arof, S., Norhisam, M., \& Iqbal, A. K. M. P. (2019b). Design and analytical study of tubular linear electromagnetic pulsing motor as an alternative for electric vehicle. In Proceedings of the 3rd International Conference on Automotive Innovation Green Energy Vehicle (Vol. 2059, No. 1, p. 020016). Maryland, USA: American Institute of Physics Inc. doi: https://doi.org/10.1063/1.5085959 
Say, M. G., \& Taylor, E. O. (1982). Direct current machines in introductory. London, UK: Pitman.

Sgobba, S. (2011). Physics and measurements of magnetic materials. In Proceedings, 2009 CAS-CERN Accelerator School: Specialised course on Magnets (pp. 39-63). Geneva, Switzerland: CERN.

Wheeler, H. A. (1982). Inductance formulas for circular and square coils. Proceedings of the IEEE, 70(12), 1449-1450. doi: 10.1109/PROC.1982.12504 
